\title{
IS THE HISTORY OF AN ANCIENT POTTERY WARE CORRELATED WITH ITS MÖSSBAUER SPECTRUM ?
}

\author{
N. H. J. GANGAS, I. SIGALAS and A. MOUKARIKA \\ Physics Department, University of Ionnina, Ionnina, Greece
}

\begin{abstract}
Résumé. - Cette investigation se réfère à l'existence des effets du vieillissement dans des poteries anciennes. La dépendance des dimensions des oxides du fer dans des échantillons de poterie moderne sour diverses conditions de cuisson, les résultats obtenus de la recuisson des échantillons de poterie ancienne et les résultats obtenus par la soustraction chimique de leurs oxides de fer indiquent fortement que la présence des particules d'oxide très fines dans les céramiques anciennes est due en partie au vieillissement.

Cette indication est en plus supportée par des résultats sur le vieillissement artificiel des échantillons de poterie moderne par un traitement de fatigue due à leur soumission aux cycles thermiques.
\end{abstract}

\begin{abstract}
This investigation refers to the existence of aging effects in ancient pottery wares. The dependence of the size of iron oxides in modern pottery samples prepared under various firing conditions, data from refiring ancient sherds and data from the chemical removal of their iron oxides strongly indicate that the presence of very fine oxide particles in the ancient ware is partially due to aging. This indication is further supported from results from the artificial « aging 》 of modern pottery samples via a fatigue treatment based on thermal cycling.
\end{abstract}

1. Introduction. - Since the first exploratory application [1] of Mössbauer effect as a tool to answer archaeological questions on ancient pottery wares, few more investigations have been performed towards this aim. Their results indicate the possible existence of correlations between Mössbauer parameters from spectra of ancient pottery sherds and their provenance [1, 2], their colours [3, 4] and their age [5]. These findings although they are quite encouraging for the potential usefullness of Mössbauer Spectroscopy to disentangle archaeological problems in the important field of pottery, they have to be ultimately understood on the basis of the physicochemical transformations occuring to iron along the history of an ancient pottery ware i. e. from its production until today. Only few detailed and systematic studies towards this aim exist up to now and their results have been recently reviewed by Kostikas et al. [6] and Coey [7].

In this work we present part of the results of our investigation - mainly via Mössbauer Spectroscopy - of the transformations occuring in the iron present in modern clay upon firing, in ancient pottery wares upon refiring and in modern ceramic samples upon artificial erosion. The aim of this investigation is to elucidate the existence of aging effects in the ancient pottery wares.

Although, the existence of such effects has been indicated by a correlation of the size of the iron oxides and the age of only few ancient Greek pottery sherds [5] and of a group of Brasilian pottery wares studied by Danon (1), it deserves special attention because of its great importance to Archaelogy and Ceramic Technology, if eventually such a correlation would be established.

The next section refers to the size of the iron oxide particles present in modern clays upon different firing conditions and to the difference observed in the size of these oxides between ancient and modern pottery.

Experimental evidence supporting the view that ancient pottery wares have aged is presented in section 3 .

In section 4 we present results on artificially eroding modern pottery wares before and after they have been subjected to a fatigue treatment based on thermal cycling.

The last section comprises concluding remarks on the problems which deserve further investigation.

2. Size of Iron Oxides. - In the studies of the form of iron present in an Attic clay [8] and of the transformations occuring to iron upon firing this clay in air [9] it was found that : a) in the clay, iron is present in the lattice of the clay mineral platelets (structural iron) as well as in the form of fine oxide or hydroxide particles of about $100 \AA$ in diameter, $b$ ) firing the clay to pottery results to an increase in size of the iron oxide particles, $c$ ) this increase occurs at two different regions of the firing temperature. The one around $300^{\circ} \mathrm{C}$ is related to the transformation of the hydroxides to haematite, while the other bet-

(1) Private communication 1976 and C6-19. 
ween $800^{\circ} \mathrm{C}$ and $900^{\circ} \mathrm{C}$ is related to the migration of the structural iron out of the clay mineral platelets. Similar results were also obtained by Hess and Perman [4] in experiments with clays from Cyprus and Israel. However, the published [2, 3, 4, 10, 11, 12] or measured by us Mössbauer spectra of many ancient pottery sherds of different styles, texture, fineness, provenance and age show in about $80 \%$ of the cases that the size of their iron oxides is significantly smaller than that found upon firing modern clays in air.

Due to the importance of this difference in the size of the iron oxides between ancient and modern pottery samples and since ancient potters varried the firing conditions in their kilns from oxidizing to reducing and vice versa [13], we investigated the dependence of the size of the iron oxides upon different firing temperatures and also upon different firing armospheres.

Samples of Attic clay were fired according to the step firing scheme used in a previous work [9] under the following firing conditions: (i) up to $600^{\circ} \mathrm{C}$ in air, (ii) up to $800^{\circ} \mathrm{C}$ in air, (iii) up to $900^{\circ} \mathrm{C}$ in air, (iv) up to $900^{\circ} \mathrm{C}$ in vacuum and (v) up to $800^{\circ} \mathrm{C}$ in air, then up to $950^{\circ} \mathrm{C}$ and down to $800^{\circ} \mathrm{C}$ in a reducing atmosphere produced by the oxygen deficient burning of saw dust and carbon powder and finally cooled below $800^{\circ} \mathrm{C}$ in air. This last firing cycle simulated the firing "of ancient Attic potters [13]. Mössbauer spectra of $150 \mathrm{mg}$ of the above samples were obtained at temperatures ranging from $4.2 \mathrm{~K}$ up to $573 \mathrm{~K}$. These spectra were analysed via a computer program enabling the use of up to four iron sites. The results from this analysis are presented in brief below.

Comparing the values of the hyperfine paramenters and the fractions of the absorption areas at different measuring temperatures (Table I presents part of these data) we deduced that : (i) the transformation of the hydroxides to hematite occurs independently of the firing atmosphere, as no oxygen is needed for this process and (ii) the increase of the iron oxide particles due to the migration of structural iron out of the clay lattice is controlled by the reducing character of the firing atmosphere. Furthermore, we note that for the sample fired under conditions simulating those of the ancient Attic potters the size of iron oxide particles is between those of the samples fired in vacuum and in air at $900^{\circ} \mathrm{C}$.

\section{TABLE I}

Mössbauer data for clay samples fired under various conditions : (i) in air up to $600^{\circ} \mathrm{C}(600)$ and $900^{\circ} \mathrm{C}(900)$, (ii) in vacuum up to $900^{\circ} \mathrm{C}(900-\mathrm{V})$ and (iii) in a firing cycle simulating ancient kiln conditions (950-S). Isomer shifts are given relative to $a^{57} \mathrm{Co}$ in $\mathrm{Cu}$ source at $4.2 \mathrm{~K}$ and $T_{\mathrm{m}}$ is the temperature of measurement. Number in parentheses give estimated errors in the last digit.

\begin{tabular}{|c|c|c|c|c|c|c|}
\hline Sample & $\begin{array}{c}T_{\mathrm{m}} \\
(\mathrm{K})\end{array}$ & $\begin{array}{c}H_{\mathrm{eff}} \\
(\mathrm{kG})\end{array}$ & $\begin{array}{l}e^{2} q Q / 4 \\
(\mathrm{~mm} / \mathrm{s})\end{array}$ & $\begin{array}{c}\delta \\
(\mathrm{mm} / \mathrm{s})\end{array}$ & $\underset{(\mathrm{mm} / \mathrm{s})}{H W H M}$ & $\begin{array}{c}\text { Fraction } \\
(\%)\end{array}$ \\
\hline \multirow[t]{6}{*}{600} & $\left.4, \overline{2(*)}^{*}\right)$ & $527 \overline{(1)}$ & $-0.091(2)$ & $0.138(2)$ & $0 . \overline{27}$ & 75 \\
\hline & & - & 0.336 & $0.15 \quad(1)$ & $0.30(3)$ & 9 \\
\hline & & - & 0.8 & $0.10 \quad(1)$ & $0.37(3)$ & 16 \\
\hline & 295 & $469_{-13}^{+10}(* *)$ & -0.14 & 0.13 & $0.25(2)$ & 45 \\
\hline & & - & 0.44 & 0.12 & $0.48(2)$ & 44 \\
\hline & & - & 0.8 & 0.14 & $0.40(2)$ & 11 \\
\hline \multirow[t]{4}{*}{900} & 4,2 & $533(1)$ & $-0.089(2)$ & 0.13 & $0.27(3)$ & 96 \\
\hline & & 一 & 0.30 & 0.13 & $0.26(2)$ & 4 \\
\hline & 295 & $494_{-16}^{ \pm 6}(* *)$ & -0.10 & 0.13 & $0.23(2)$ & 82 \\
\hline & & - & 0.31 & $0.08 \quad(1)$ & 0.25 & 18 \\
\hline \multirow[t]{7}{*}{$900-\mathrm{V}$} & 4,2 & $533(1)$ & $-0.089(2)$ & 0.13 & $0.32(3)$ & 78 \\
\hline & & - & 1.24 & $1.00 \quad(5)$ & 0.40 & 11 \\
\hline & & - & 0.44 & 0.13 & 0.59 & 11 \\
\hline & 295 & $501(1)$ & -0.13 & $0.09 \quad(1)$ & 0.25 & 51 \\
\hline & & - & 1.04 & 0.63 & 0.4 & 9 \\
\hline & & - & 0.62 & $0.55 \quad(2)$ & 0.4 & 13 \\
\hline & & - & 0.34 & $0.0 \quad$ (1) & 0.3 & 27 \\
\hline \multirow[t]{4}{*}{$950-\mathrm{S}$} & 295 & $499(2)$ & -0.12 & 0.14 & 0.22 & 65 \\
\hline & & - & $0.95 \quad(1)$ & $0.77 \quad(2)$ & 0.25 & 8 \\
\hline & & - & 0.70 & $0.68 \quad(2)$ & 0.31 & 5 \\
\hline & & - & $0.31 \quad$ (1) & $0.10 \quad(2)$ & 0.25 & 22 \\
\hline
\end{tabular}


The variation of the bloking temperature [8], in Attic clay upon firing temperature and firing atmosphere is pictured in figure 1 via the temperature dependence of the superparamagnetic ratio [8]. In the same figure we plotted also the ratio $(R)$ of the paramagnetic to the total absorption area for few typical ancient sherds [5] of different provenance and age. From this data one observes that the bloking temperature which is proportional to the oxide particles' mean volume, falls for the ancient sherds several times smaller than that for the modern clay samples fired either as low as $600^{\circ} \mathrm{C}$ in air or at $900^{\circ} \mathrm{C}$ in vacuum (about $10^{-5} \mathrm{mmHg}$ ).

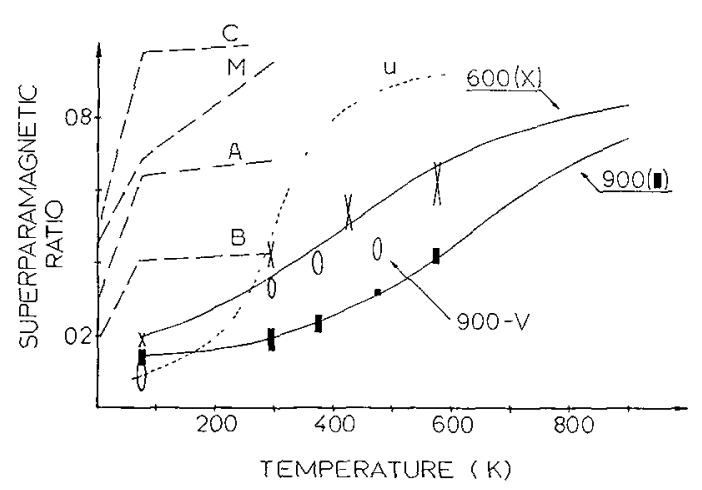

FIG. 1. - The superparamagnetic ratio at various temperatures for the clays samples fired in air at $600{ }^{\circ} \mathrm{C}(600)$, at $900^{\circ} \mathrm{C}(900)$ and fired in vacuum at $900^{\circ} \mathrm{C}(900-\mathrm{V})$. The full drawn curves result from a least square's fitting via a lorenzian distribution for the volumes of the oxide particles [8]. The dotted curve is the superparamagnetic ratio of the unfired clay from Ref [8]. The dashed lines represent the gross features of the $R$-ratio of the ancient samples : $\mathrm{A}=\mathrm{Attic} ; \mathrm{B}=$ Byzantine ; $\mathrm{C}=$ Mycenean; $M=$ Minoan [5]

The origin of this difference cannot be entirely due to the use by ancient potters of clays with either smaller iron content or oxides and hydroxides of significantly smaller size than those of our modern clays, since ancient and modern pottery samples have comparable amounts of iron [13]. Moreover, in experiments [4] with a clay having initially oxide particles as small as about $40 \AA$, firing of this clay at $850^{\circ} \mathrm{C}$ either in air or in argon produced oxide particles with a blocking temperature greater than $300 \mathrm{~K}$, as can be estimated from the published Mössbauer spectra.

Our present knowledge on the depedence of the size of iron oxides with firing conditions cannot fully account for the difference observed in the sizes of these oxides between ancient and modern pottery samples.

3. Aging Effects. - The presence of phenomena due to the operation of aging mechanisms during the life of ancient pottery wares is expected on the ground of results from the chemical analysis of ancient glasses [14]. These results show that for the decomposition of glass long buried in soil : (i) water is the primary agent, (ii) the final decomposition product resulting from hydrolysis and dissolution processes is a porous residue of impure silica and (iii) while alkalies are more or less completely removed from the altered part of the glass, iron oxide is found in the altered part at least in the same weight percentage as in the unaltered glass.

In order to investigate whether the difference in the size of the iron oxide particles between ancient and modern pottery samples could be at least partially attributed to aging effects on ancient sherds, we investigated the degree of decomposition of several ancient Greek pottery samples, by measuring the amount of iron oxide removed from these samples by dithionite dissolution. The procedure destribed by Roth et al [15] has been used, since it is very efficient in removing free iron oxides from clay while it has practically no effect when applied on clay fired above about $800^{\circ} \mathrm{C}$ due to the sintering occuring above this temperature. From the Mössbauer spectra of the ancient sherds follows that: $a$ ) these sherds loose about $30 \%$ of their iron upon the action of the above chemical treatment and $b$ ) the blocking temperature of the iron oxide particles in the sherds decreased by at about $50 \%$. Since it can be assumed [13] that ancient pottery wares of acceptable quality have been fired at temperatures higher than $800^{\circ} \mathrm{C}$, the observed effectiveness of the applied chemical treatment in removing from them a large part of their iron oxides indicates that these samples suffered an aging which resulted to an uncovering of these oxides. This uncovering exposed the oxides to eroding agents which reduced the oxides' size in a time scale of the order of thousand years. Taking into account the extremelly small solubility of trivalent iron and the easiness of reoxidizing divalent iron one may assume that the products of the weathering did not migrate out of the ware. This assumption is supported by the above mentioned data on ancient glasses and also by the fact that optical spectroscopy [13] as well as Mössbauer spectroscopy show that ancient sherds and modern pottery have comparable amounts of iron.

Furthermore, results upon refiring ancient pottery sherds showed that a significant increase of the size of the iron oxide particles occured above $1000^{\circ} \mathrm{C}$ firing temperature (Fig. 2). A similar increase in the amount of the magnetic component of the Mössbauer spectrum at the expense of the paramagnetic one has been found by Keish [16] upon refiring around $1000^{\circ} \mathrm{C}$ samples of ancient terracota figures.

The refiring data can be interpreted as manifesting the fusion of the iron oxide particles which resulted from the erosion of the initially large ones. This fusion is possible for fine (about $80 \AA$ in diameter) iron oxide particles being in contact to each other, since 


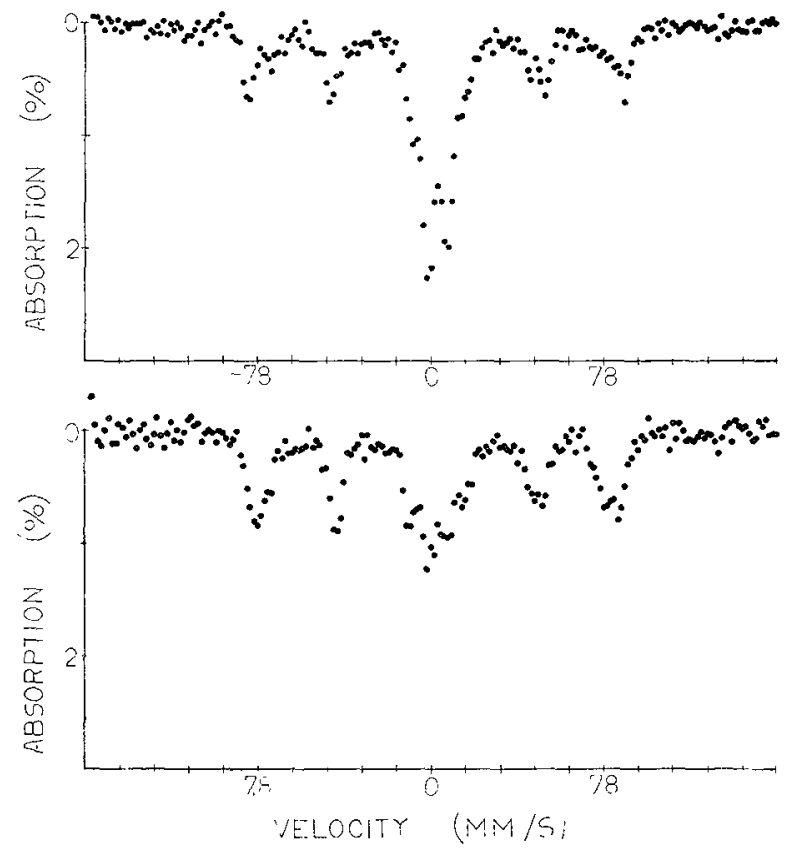

FIG. 2. - Mössbauer spectra at $80 \mathrm{~K}$ of a typical ancient Greek pottery sherd before (upper) and after (lower) refiring at $1100^{\circ} \mathrm{C}$.

the melting point of small hematite particles is estimated to be as low as about $1000^{\circ} \mathrm{C}$ (2).

Summarizing, we conclude that there is definite experimental evidence supporting the view that ancient pottery wares suffered a weathering action.

4. Artificial Aging. - Ceramics show state fatigue effects due to the disruption of the Si-O-Alkaline networks [17]. The breaking of the bonds starts at the edges of the ceramic grain boundaries via the action of water. This hydrolysis of the network is autocatalytic, since excess hydroxyl ions are form, which increase the $\mathrm{pH}$ whithin the corrosion region. Furthermore, DTA-data [18] show that certain clay minerals, particularly the illites and montmorillonites, regain quite fast i. e. whithin few decades of days, some hydroxyl water as well as adsorbed water on standing at room temperature after being dehydrated to temperautre as high as $800^{\circ} \mathrm{C}$. Therefore, the production of grain boundaries and humidity can be considered as the main factors inducing with time an increase in the porosity of ceramics. Boundaries are produced by microcracks of the ceramic grains and such microcracks can easily be produced because of boundary stresses due to differences in the thermal expansion coefficient in the ceramic.

The above physicochemical processes and the experimental evidence presented in section 3 on the

(2) This results by taking into account : (i) that the surface molecules in a small particle represent a significant portion of the total number of the molecules of the particle and (ii) that the binding energy of the surface molecules is smaller than that of the molecules in the inner parts of the particle. aging effects in ancient pottery wares and ancient glasses [14] render relevance to the hypothesis that these aging effects are possibly the results of the following mechanism : The daily temperature change and humidity, over a time scale of hundreds or thousands years, increase the porosity of a pottery ware and thus enable the erosive dissolution of iron from the originally, i. e. after the firing of the pottery large iron oxide particles. The dissolution is followed by a subsequent redeposition upon reoxidation of the divalent iron at a near by place in the ceramic.

In what follows we present in brief results from an exploratory series of experiments testing the effectiveness of thermal cycling as a mechanism reducing the resistance of modern fired clay samples to erosive removal of their iron oxides.

Powdered samples of Attic clay fired in air up to $900^{\circ} \mathrm{C}$, have been subjected to two different types of thermal cycling procedures. In the first type (I) the samples were cycled from about $-110^{\circ} \mathrm{C}$ to $+30^{\circ} \mathrm{C}$ in $40 \mathrm{sec}$. The total number of cycles performed was 10000 . The second type (II) of cycling simulated in every cycle the average daily temperature change, i. e from about $10^{\circ} \mathrm{C}$ to $25^{\circ} \mathrm{C}$. The cycling time was about $5 \mathrm{sec}$ and the samples performed a number of cycles equal to about 700 years. No sample was subjected to both types of cycling.

Each thermally cycled ceramic sample and an equal amount of ceramic which has not been thermally fatigued and hence served as reference were simultaneously subjected to two identical dithionite dissolution treatments. By filtering each of the two suspensions we separated the ceramic powders from the solutions which carried the iron that has been removed by this chemical treatment from the samples. The relative amounts of iron present in the solutions have been determined by measuring the optical absorption at wavelentgth $510 \mathrm{~nm}$ of the solutions after adding to them the indicator orthophenarthroline.

These data show that the samples which have been subjected to thermal cycling lost systematically greater amounts of iron than the reference samples. Specifically, the applied dithionite treatment removed about $20 \%$ and $60 \%$ more iron from the ceramic samples which were subjected to thermal cycling type I and II respectively, than from the reference samples. These results are compatible with the expectation that the thermal cycling produced cracks in the ceramic grains and thus increased the effectiveness of removing chemically iron from them.

Mössbauer spectra of the reference, the thermal cycled samples prior and after they have been subjected to dithionite dissolution treatments and in few special cases spectra also of the filtered solution after drying and calcination at $500^{\circ} \mathrm{C}$ were obtained at various temperatures in order to make certain that the applied chemical treatment did not alter the chemical nature of the iron compounds of the samples 
and also to monitor the dissolved iron and the particle size of the iron oxides of the samples. These spectra support the results of the optical absorption measurements and also show that : (i) before the dithionite treatment, the Mössbauer spectra of the reference sample as well as of the thermally fatigued sample are identical and (ii) after chemical treatment the thermally cycled ceramic samples have finer iron
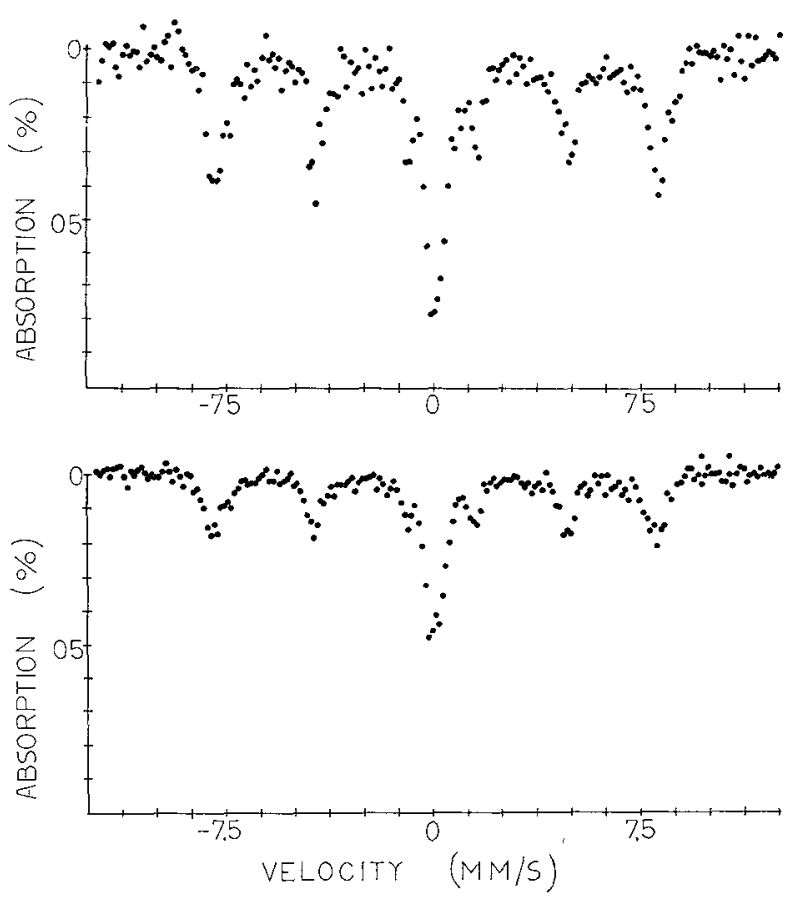

FIG. 3. - Mössbauer spectra at $295 \mathrm{~K}$ of chemically treated modern pottery samples with a ceramic grain of about $10 \mu$ : non-fatigued sample (upper), sample fatigued by thermal cycling (lower). oxide particles than the also chemically treated reference ceramic (Fig. 3).

5. Conclusion. - We conclude this brief presentation of our still ongoing investigation on the existence and the nature of aging effects in ancient pottery wares with the following remarks :

(a) The existing data-on the dependence of the size of the iron oxides upon firing various clays under different firing conditions allow the conclusion that the small size of these oxides in ancient sherds is at least partially due to wearthering.

(b) Firing temperature is a variable of major importance for the degree of erosion of ancient pottery wares, since it is related to the initial porosity of these wares. Its aproximate value can be only infered at present.

(c) The results on artificial aging of modern pottery samples present strong indication that similar processes are operative in the erosion of ancient pottery wares.

Although much more work is still needed before one will clarify the correlation between the Mössbauer spectra and the history of an ancient sherd, the presently available data point out that this correlation will supply valuable information to Archaeology.

We express our thanks to Drs A. Kostikas and A. Simopoulos for making available to us the liquid helium at N. R. C. Democritus and for their valuable comments on the manuscript. Thanks are also due to Dr. Papageorgopoulos for his vivid interest and positive interaction in this work, to Mr. P. Benekos for his support on the technical part of this work and to Mr. Th. Bakas for his assistance in the running of the experiments.

\section{References}

[1] Cousins, D. R. and Dharmawardena, K. G., Nature 223 (1969) 733.

[2] Kostikas, A., Simopoulos, A. and Gangas, N. H., $J$. Physique Colloq. 35 (1974) C1-107.

[3] Bouchez, R., Coey, J. M. D., Coussement, R., Schmidt, K. P., Van Rossum, M., Aprahamian, J. and Deshayes, J., J. Physique Colloq. 35 (1974) C6-541.

[4] Hess, J. and Perlman, I., Anchaeometry 16 (1974) 137.

[5] Kostikas, A., Simopoulos, A. and Gangas, N. H., $J$. Physique Colloq. 35 (1974) C6-537.

[6] Kostikas, A., Simopoulos, A. and Gangas, N. H., Applications of Mössbauer Spectroscopy, I., Edited by R. L. Cohen Published by (Academic Press, New York) 1975.

[7] CoEY, M. D., Proceedings of the International Conference on Mössbauer spectroscopy Krakow 25-30 August 1975. Edited by A. Z. Wrynkiewicz and Z. A. Sawicki.

[8] Gangas, N. H., Simopoulos, A. Kostikas, A., Yassogloy, N. and FILIPPAKIs, S., Clays and Clay Miner. 21 (1973) 393.

[9] Simopoulos, A., Kostikas, A., Sigalas, I., Gangas, N. H. and MoukarikA, A., Clays and Clay Miner. 23 (1975) 393.

[10] Longworth, G. and Warren, S. E., Nature 255 (1975) 625.

[11] Eissa, N. A., Salam, H. A. and Keszthelyt, L., $J$. Physique Colloq. 35 (1974) C6-569.

[12] Janot, C. and Delcrorx, P., J. Physique Colloq. 35 (1974) C6-557.

[13] Noble, J. V., The Techniques of Painted Attic Pottery, (Published by Faber, London) 1966.

[14] CALEY, E. R., Analyses of Ancient glasses 1790-1957, (Published by the Corning Museum of glass, New York) 1972, pp. 105-113.

[15] Roth, C. B., JACKson, M. L., Lotse, E. G. and SeYers, J. K. Isr. J. Chem. 6, 261.

[16] KeIsCH, B., Application of Mössbauer spectroscopy, I., Edited by R. L. Cohen Published (Academic Press, New York) 1975.

[17] KINGERY, W. D., Introduction to Ceramics, (John Wiley \& Sons, Inc., New York) 1960, pp. 611-618.

[18] Grim, R. E. and Bradlex, W. E., Amer. Miner., 33 (1948) 50. 